\title{
Effect of liquid organic fertilizer "Efflurost" on economically valuable indicators of vegetable crops
}

\author{
Nadejda Kotsareva ${ }^{1 *}$, Petr Tolmachev ${ }^{2}$, Vladimir Bredihin ${ }^{3}$, and Dmitrii Ohrimchuk ${ }^{4}$ \\ ${ }^{1}$ FSBEI HE Belgorod State Agricultural University named after V.Gorin, Belgorod, Russia \\ ${ }^{2}$ LLC "AGROSNABSPAVKA", Belgorod, Russia \\ ${ }^{3}$ LLC "AltEnergo", Belgorod, Russia \\ ${ }^{4}$ LLC "Belgorod Institute of Alternative Energy", Belgorod, Russia
}

\begin{abstract}
The results of determining the application dose of liquid organic fertilizer "Efflurost" and its effect on economically valuable indicators of sweet pepper and eggplant, agrochemical parameters of the soil are presented. The positive effect of liquid organic fertilizer "Efflurost" on economically valuable indicators of vegetable crops (sweet pepper and eggplant) and on the soil agrochemical parameters has been established. The optimal application rates of liquid organic fertilizer "Efflurost" for sweet pepper is 1:10 dilution and 1: 5 for eggplant, which bring to yield enhancement of marketable products by $10.6 \mathrm{t} / \mathrm{ha}$ and $27.2 \mathrm{t} /$ ha respectively. Soil acidity decreasing by 0.1-0.4 units, the number of microorganisms involved in the mineralization of humic substances and increasing the number of ammonifying microorganisms were noted.
\end{abstract}

\section{Introduction}

For many years the Belgorod region has been a leader in the meat production. Today the Belgorod region ranks second in pork production among the federation subjects and on the top in poultry production. The volume of meat and poultry production in the region is more than 1.7 million tons per year. Along with the positive aspects the industrialization of livestock breeding brings certain problems - utilization of a huge amount of agricultural waste (manure and bird droppings, processing livestock and crop products waste) with the future use as organic fertilizers [1].

Under scientific approach the efficient use of agricultural waste allows us to reduce mineral fertilizers purchase significantly and to produce own organic fertilizers. According to the current "Rules for the disinfection of manure, litter and sewage" as well as the "Veterinary and sanitary rules for preparing manure and sewage for use as organic fertilizers under infectious and invasive diseases of animals and birds" one of the methods of disinfection and preparation for use of organic fertilizers is their processing in anaerobic conditions. During anaerobic treatment biomass undergoes biodecontamination as a result of which nonspore-forming pathogens of infectious diseases, viable larvae and worm eggs, flies' pupae and larvae, intestinal protozoa cysts die $[2,3,4]$.

Biogas station "Luchki" of "AltEnergo" company produces three types of organic fertilizers. In anaerobic mesophilic reactors biomass (pork and cattle runoff, livestock and crop production waste) under the influence of hydrolysis reactions and various groups of microorganisms at the temperature of $38-41^{\circ} \mathrm{C}$ for $30-50$ days is processed into biogas and three types of organic fertilizers, one of which is liquid organic fertilizer "Efflurost".

\section{Experimental}

The research of the effect of liquid organic fertilizer "Efflurost" on economically valuable indicators of vegetable crops (sweet pepper and eggplant) was carried out at the Department of Horticulture, Selection and Vegetable Production at the Belgorod State Agricultural University named after V. Gorin in 2019.

To achieve these goals, the following tasks were set and solved: phenological and biometric measurements were carried out on sweet pepper and eggplant, leaf diagnostics and soil agrochemical analysis were done, the optimal doses of liquid organic fertilizer "Efflurost" for sweet pepper and eggplant were determined.

The laying of the experimental plots and the processing of the obtained data were carried out according to existing methods $[5,6]$.

Liquid organic fertilizer "Efflurost" was added under pepper and eggplant - 11 / per 1 plant with a dilution of 1 : $3,1: 5,1: 10$, the control is water. The sample of pepper and eggplant is 20 plants for each option. Phenological observations and plants biometric measurements were done before application of liquid organic fertilizer "Efflurost" and in 10 days.

\footnotetext{
* Corresponding author: knv1510@mail.ru
} 
Soil analysis can`t demonstrate how efficiently plants absorb nutrients from the soil. Plant tissues analysis is a fairly economical and strategic tool for monitoring of plants growth and development; therefore, it was done leaf diagnosis and soil agrochemical analysis according to the options. Leaf diagnosis allows us to determine the condition of plants during blossom time as well as nutrition problems at the moment. Leaf diagnosis is especially important for adverse external factors that make it difficult for the root system to absorb nutrients from the soil. Leaf diagnosis can demonstrate the current plants state and in particular a deficit of one or another element. Leaf diagnosis used during blossom time can be visual, chemical and functional.

\section{Results and discussions}

The effect of liquid organic fertilizer "Efflurost" on the increasing of crops vegetative mass was multivalued. The largest increase in tops for 10 days after application of liquid organic fertilizer "Efflurost" was observed in sweet pepper plants in the dilution of 1:10 (Fig.1).

Plant gain of sweet pepper in the control amounted to $14 \%$ and with a 1:10 dilution of liquid organic fertilizer "Efflurost" the height increased by $81 \%$.

The best results of plant gain of eggplant were obtained at the dilution 1: 3 and 1: 5 (84\% and 93\%) (Fig.2).

During leaf diagnosis of sweet pepper in the control and at a dilution of 1:3 it was determined overdose of nitrogen $-11 \%$, while at a dilution of $1: 5$ and $1: 10$ it was found a lack of nitrogen - 10\%. A lack of phosphorus and potassium has been also noted.

During leaf diagnosis of eggplant it was determined overdose of nitrogen in the control $-15.5 \%$, in the option with a dilution of 1: $3-10 \%$, with a dilution of 1:10 $14 \%$. A lack of phosphorus was found in the control and with a dilution of 1: 3 . Overdose of potassium was found in eggplant leaves at a dilution of $1: 3-16.3 \%$, a lack of potassium was found at a dilution of $1: 10$ of liquid organic fertilizer "Efflurost"- 19.6\%.

The effect of application of liquid organic fertilizer "Efflurost" on the yield indicators of vegetable crops was determined (table 1).

The mass of sweet pepper fruits varied from $37.5 \mathrm{~g}$ in the control to $39.0 \mathrm{~g}$ according to the application options. There were from 13 fruits in the control to $16-18$ ones in the options.

The largest yield gain was noted in sweet pepper when using liquid organic fertilizer "Efflurost" at a dilution 1:10, which was $10.6 \mathrm{t} / \mathrm{ha}$. The fruit weight of eggplant was 194-195 g with a load of 9-11 fruits per plant. The gain from the application of liquid organic fertilizer "Efflurost" was greatest at a dilution of 1: $5-27.2 \mathrm{t} / \mathrm{ha}$.

The soil agrochemical analysis was done at the end of growth. As a result of the soil agrochemical analysis it was noticed decrease of soil acidity by 0.1-0.4 units under application of liquid organic fertilizer "Efflurost" (Table 2).

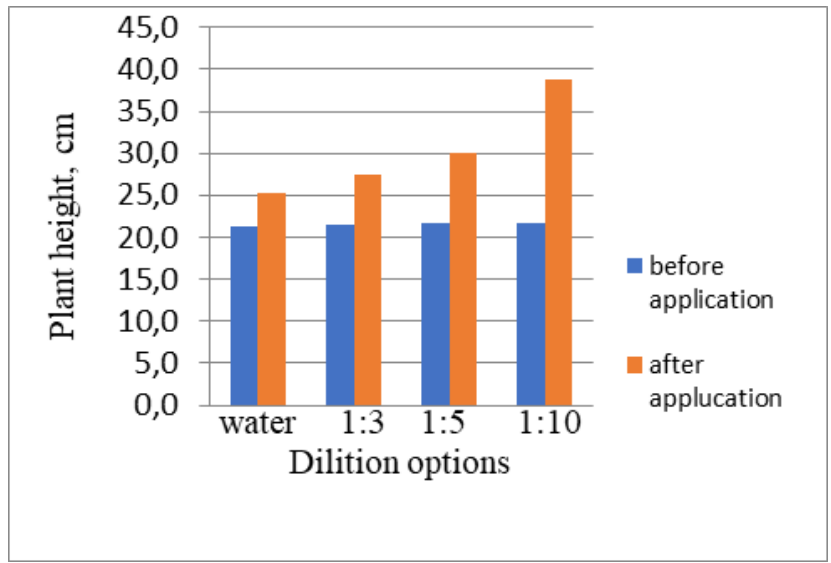

Fig. 1. Plant gain of sweet pepper depending on the concentration of liquid organic fertilizer "Efflurost".

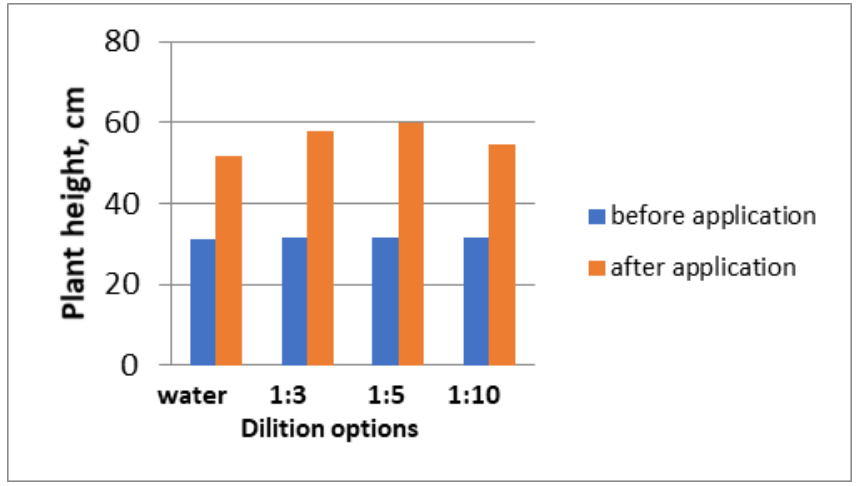

Fig. 2. Plant gain of eggplant depending on the concentration of liquid organic fertilizer "Efflurost".

The mass content of total nitrogen and phosphorus in the soil decreased under application of liquid organic fertilizer "Efflurost" at a dilution of 1:3 and 1:10 and the potassium indicators increased in comparison with the control.

Beneficial microorganisms contribute to the conversion of insoluble soil elements and fertilizers into accessible forms, fix atmospheric nitrogen and release biologically active substances: vitamins, growth stimulants and other useful substances. At the same time, they can also cause negative processes for plants: biological immobilization, gaseous nitrogen decline during denitrification and some microbes release poisons.

Under application of liquid organic fertilizer "Efflurost" at a dilution of 1:3 it was noticed decreasing of the number of ammonifying microorganisms up to $5.3 \times 106 \mathrm{CFU} / \mathrm{g}$, but the number of microorganisms using mineral forms of nitrogen decreased from $4.8 \times 106 \mathrm{CFU} / \mathrm{g}$ in the control to $4.7 \times 106 \mathrm{CFU} / \mathrm{g}$ at a dilution of $1: 3$ and up to $4.5 \times 106 \mathrm{CFU} / \mathrm{g}$ at a dilution of $1: 10$. It was noted a decreasing of microorganisms involved in the mineralization of humic substances from 3.7x106 CFU/g in the control to $3.0 \times 106 \mathrm{CFU} / \mathrm{g}$. 
Table 1. Effect of liquid organic fertilizer "Efflurost" on the yield of vegetable crops.

\begin{tabular}{|c|c|c|c|c|c|}
\hline Crop & Options & Mass, $\mathrm{g}$ & Fruits per plant, units & $\begin{array}{c}\text { Crop yield, } \\
\text { t/ha }\end{array}$ & $\begin{array}{c} \pm \\
\text { to the control }\end{array}$ \\
\hline \multirow{4}{*}{ Sweet pepper } & Water is the control & 37,5 & 13 & 26,7 & - \\
\hline & $1: 3$ & 38,5 & 16 & 32,6 & $+5,9$ \\
\hline & $1: 5$ & 38,5 & 16 & 34,9 & $+8,2$ \\
\hline & $1: 10$ & 39,0 & 18 & 37,3 & $+10,6$ \\
\hline \multicolumn{6}{|c|}{ least mean difference 05} \\
\hline \multirow{4}{*}{ Eggplant } & Water - control & 194 & 9 & 52,4 & - \\
\hline & $1: 3$ & 195 & 10 & 74,2 & $+21,8$ \\
\hline & $1: 5$ & 197 & 11 & 79,6 & $+27,2$ \\
\hline & $1: 10$ & 195 & 9 & 67,3 & $+14,9$ \\
\hline \multicolumn{6}{|c|}{ least mean difference 05} \\
\hline
\end{tabular}

Table 2. Soil agrochemical analysis under application of liquid organic fertilizer "Efflurost".

\begin{tabular}{|c|c|c|c|}
\hline \multirow{2}{*}{ Indicators } & \multicolumn{3}{|c|}{ Application options } \\
\cline { 2 - 4 } & Without application & Dilution 1:3 & Dilution 1:10 \\
\hline Salt extract pH, units & $6,9 \pm 0,1$ & $7,0 \pm 0,1$ & $7,3 \pm 0,1$ \\
\hline Total nitrogen content, \% & $0,23 \pm 0,03$ & $0,22 \pm 0,03$ & $0,21 \pm 0,03$ \\
\hline Total phosphorus content, \% & $0,22 \pm 0,016$ & $0,20 \pm 0,014$ & $0,20 \pm 0,014$ \\
\hline Total potassium content, \% & $1,88 \pm 0,24$ & $1,94 \pm 0,24$ & $1,94 \pm 0,24$ \\
\hline \multicolumn{2}{|c|}{ Microbiological indicators (depth 15 sm) } \\
\hline Ammonifying microorganisms, CFU/g & $7,6 \times 10^{6}$ & $3,7 \times 10^{6}$ & $7,9 \times 10^{6}$ \\
\hline $\begin{array}{c}\text { Microorganisms using mineral forms of } \\
\text { nitrogen (including actinomycetes),CFU/g }\end{array}$ & $3,0 \times 10^{6}$ & $2,9 \times 10^{6}$ \\
\hline $\begin{array}{c}\text { Microorganisms involved in humic } \\
\text { substances mineralization, CFU/g }\end{array}$ & $1,7 \times 10^{6}$ & $1,9 \times 10^{6}$ & $1,9 \times 10^{6}$ \\
\hline $\begin{array}{c}\text { Azotobacter (nitrogen-fixing } \\
\text { microorganisms), \% }\end{array}$ & 60 & 60 & 60 \\
\hline
\end{tabular}

\section{Conclusion}

The positive effect of liquid organic fertilizer "Efflurost" on economically valuable indicators of vegetable crops (sweet pepper and eggplant) and on the soil agrochemical parameters has been found. The optimal application rates of liquid organic fertilizer "Efflurost" have been determined to yield enhancement of vegetable crops and soil fertility.

The largest yield gain was noted in sweet pepper under application of liquid organic fertilizer "Efflurost" at a dilution of 1:10 and in eggplant at a dilution of 1:5.

\section{References}

1. V.D. Solovichenko, S. I. Tyutyunov, V. V. Nikitin, and E. V. Navoleneva, "Pork runoff is a valuable organic fertilizer", Scientific-production manual, Belgorod: Publishing House "Otchiy kray", p. 28 (2017)

2. "Instruction for the organic fertilizer production resulting from biomass anaerobic processing", Belgorod: LLC Altenergo, p.18 (2018)
3. TU 20.15.80-001-76522675-2018. "Organic fertilizer based on pig manure", URL: // www: // http: //docs.cntd.ru/document/437232067.

4. "Veterinary and sanitary rules for the preparation of manure, litter and sewage for the use as organic fertilizers in infectious and invasive diseases of animals and birds" // URL: // https: //www.fsvps.ru/fsvps/laws/164.htm.

5. B.V. Dospehov, "Methodology of experimental work"( Kolos, Moscow, 1982)

6. S. S. Litvinov, "Methodology of experimental work in vegetable growing (GNU VNIIO, Moscow, 2011) 